\title{
Root Cause Analysis of Generation of Chatters in Crankshaft Pin Grinding
}

\author{
Vinod Hange \\ Department of Manufacturing Engineering \\ MGM College of Engineering, Aurangbad \\ Prof. Dilip Khedekar \\ Faculty of Mechanical Engineering Department \\ MGM College of Engineering, Aurangbad
}

\begin{abstract}
Chatter has long been a problem in machining and grinding. With trends for higher precision and greatly tighter tolerance, solutions to chatter problems have become increasingly important. Though chatter is simply a consequence of vibration within a grinding system, finding causes for the vibration and developing corrective strategies can be difficult. Essentially there are two types of chatter-causing vibration: forced and self excited (regenerative). The former is vibration independent of the grinding wheel and workpiece with sources that range from spindle bearings to machine tools operating nearby. Regenerative vibration, a type of chatter first described by Robert Hahn, starts as a slipslide interaction between wheel and workpiece. The focus in this work is to search for the root cause of chatters in the crankshaft pin grinding as the life and the performance can be improved by proper grinding the crankshaft pin.
\end{abstract}

Keywords - Chatter, regenerative, Spindle Bearing etc.

\section{INTRODUCTION}

Machining vibrations, also called chatter, correspond to the relative movement between the workpiece and the cutting tool. The vibrations result in waves on the machined surface. This affects typical machining processes, such as turning ,milling, drilling and a typical machining processes, such as grinding.

A chatter mark is an irregular surface flaw left by a wheel that is out of true in grinding [1] or regular mark left when turning a long piece on a lathe, due to machining vibrations.

As early as 1907, Frederick W. Taylor described machining vibrations as the most obscure and delicate of all the problems facing the machinist, an observation is still true today, as seen in many publications on machining.

Mathematical models make it possible to simulate machining vibration quite accurately, but in practice it is always difficult to avoid vibrations and there are basic rules for the machinist:

- Rigidify the workpiece, the tool and the machine as much as possible

- Choose the tool that will excite vibrations as little as possible (modifying angles, dimensions, surface treatment, etc.)

- Choose exciting frequencies that best limit the vibrations of the machining system (spindle speed, number of teeth and relative positions, etc.)

- Choose tools that incorporate vibration-damping technology.

Chatter is a common problem in grinding. There are two types of chatter: 1) forced chatter; and 2) unforced chatter, also called regenerative chatter or self-excited chatter. Forced chatter is caused by an out-of-true wheel, an out-ofbalance wheel, a bad bearing, a damaged belt, different stiffness in the planes of the spindle, uneven wear on the wheel, or something vibrating that shouldn't. Unforced chatter is caused by an excitation of the system that grows. It occurs at the natural frequency of the spindle and workpiece/tool holder. Some causes of self-excited chatter are a dull grinding wheel, a low Grit Penetration Depth, a large overlap ratio in cylindrical-traverse grinding and poor tool-holder stiffness, among others. The cause of chatter can usually be determined by measuring the distance between chatter marks and calculating the chatter frequency from the workpiece RPM or workpiece velocity. Other strategies are avoiding "integer values" and varying the speed of the wheel or workpiece. All of these concepts are taught in The Grinding Doc's grinding wheel courses, held several times per year at various locations in the U.S., Europe and Asia. 


\section{ANALYSIS OF CHATTERS}

Grinding is one of the critical machining process which is used to prepare the highest surface finish of the mating parts. Grinding process comprises of many other defects but major is chatters. This problem is especially annoying because it can be tricky to isolate the cause and the solution. When chatter occurs, it's typically not as evident as other issues like discoloration on the part due to grinding burn. Chatter usually shows up when you're inspecting your parts, so it can be a real productivity killer that has to be fixed. Here is analysis of possible causes of grinding chatter and remedies to resolve them, Here's the list of in order of what should be checked first. The possible cause can be-

\section{Grinding Cut Too Heavy-}

If in crankshaft grinding the grinding cut, that is feed of work piece relative to the grinding wheel rpm is always important. If it is higher or too heavy the chances of chatters are greater and if it is less or small chances of chatter are negligible.

So how you are controlling feed so the machine is taking a lighter cut. This will allow for your grinding wheel to cut more freely and prevent any possible vibration or bouncing.

\section{Wheel Too Hard}

For Grinding crankshaft as there is a specific need of CBN grinding wheel which we can not change. But if we could see same specific wheel of different manufacturers these are more or less hard. So if process permits use standard or a softer wheel, or make the wheel act softer.

\section{Adjusting Dress Feeds}

Try adjusting your dress feeds. By adjusting your dress feed it can allow your wheel to cut more freely with a faster feed. The drawback is that the faster you dress the higher your surface finish will be.

\section{Grinding Fluid}

Try enriching your grinding fluid. We usually run our coolant at 7\%. Try using a higher percentage of coolant to see if that helps.

\section{Cylindrical Work Unsupported}

If you're grinding Cylindrical work make sure you're using a steady rest that's suitable for the workpiece.

\section{Machine Vibration}

There are a few things to check for machine vibration some troubleshooting are:

Make sure you don't have any vibration coming from your machine. A lot of times you can get vibration because your leveling screws have become loose, or components have been left loose due to setup.

Inspect your belts to make sure you have the right belt tension and to make sure there are no defects in the belts that would cause vibration.

Check to make sure your wheel is not out of balance or cracked. If you have an auto balancer this is easy, but if you don't make sure you take your wheel out of your machine and check the balance of your wheel. Also inspect it for cracks while you have it out. Replace the wheel if it has any defects in it.

Make sure everything is tight that might cause a vibration.

As you become accustomed to checking for these variables and performing troubleshooting, you'll gain an instinctive knowledge for preventing grinding chatter. The next time it happens you'll know exactly what to look for. 


\section{PROBLEM CAUSES AND REMEDIES}

\section{Problem}

Regularly spaced marks

Wide, regularly spaced marks

Long, regularly spaced marks

Short, close, evenly spaced marks

Slightly longer and more widely spaced marks

Long, widely spaced marks

Regular or irregular marks Narrow, regularly spaced marks

Chatter vibration

Chatter

vibration
Longish, widely spaced discolored

marks, distributed evenly

Chatter marks

Irregular marks

Marks synchronized with

floor vibration

Mottle marks

Deep, narrow regular marks

\section{Possible Causes}

Vibration

Vibration from belt

Pulley loose or out of balance

Wheel out of balance

Wheel face out of round

Spindle bearings loose

Wheel spindle run-out or out of round

Drive gear backlash

Faulty thrust bearing

Spindle pulley loose

Glazed or loaded wheel

Incorrect wheel dressing

Center holes out of round or not in line

Steady rests improperly adjusted

Vibration from floor

Glazed wheel

Wheel too coarse

\section{Suggested Correction}

Re-balance motor and wheel. Replace belt.

Eliminate looseness.

Balance pulley.

Wheel face out of round.

True wheel before balancing. Adjust spindle bearings.

Warm up grinding machine to reach appropriate temperature. Check thrust bearing.

Replace wheel spindle.

Replace gears.

Introduce $\mathrm{V}$ belt drive. Check lubricated condition. Replace thrust bearing.

Tighten spindle pulley.

Use coarser grit, softer grade or more open structure wheel.

Redress wheel face with sharp diamond dresser.

Mount diamond dresser rigidly in holder.

Check work center holes for roundness ad alignment.

Check workpiece for fit to centers.

Check lubricated condition between work center holes and centers.

Adjust steady rests.

For large machines, build additional

foundation separated from floor.

For normal machines, try adjusting anchor bolts.

Try changing machine location. Mount machine on some vibration insulating material.

Balance and redress wheel. Remove grease or oil spots from wheel face. Use finer grit wheel.

\section{V.CONCLUSION}

By referring to above possible causes and remedies, if we take care for inputs related to work, work speed, coolant, grinding wheel, girding wheel dressing, depth of cut, dressing depth of cut, we can reduce the possibility of generating the chatters.

\section{REFERENCES}

[1] Determination and Optimization of Chatter, Ovality \& Surface Roughness in Crankshaft Grinding Process by Using Taguchi Method of Analysis. by Vinod Hange1, Bharat Shirke2,Munjabadas Kadam3, D.Khedekar4 and M.V.Kawade( IJAST) ISSN 2229 5216 
[2] "Grinding Overview" Virtual Machine Shop,

Web.http://www.thevms.com/vms/other_grinding/other_grinding_00.html.

[3] Mr. Ballal Yuvaraj P., Dr. Inamdar K.H., Mr. Patil P.V. / International Journal of Engineering Research and Applications (IJERA) ISSN: 2248-9622 www.ijera.com, "Application of Taguchi Method for Design of Experiments in Turning Gray Cast Iron”. Vol. 2, Issue 3, MayJun 2012, pp.1391-1397.

[4] Kocherovsky, Eugene. "50 years of technological Development." Cutting Tool Engineering. 57.8 (2005): 95-114. 